\title{
Acute myocardial infarction in systemic sclerosis patients: a case series
}

Chris T. Derk

Thomas Jefferson University

Sergio A. Jimenez

Thomas Jefferson University

Follow this and additional works at: https://jdc.jefferson.edu/medfp

Part of the Medical Genetics Commons

Let us know how access to this document benefits you

\section{Recommended Citation}

Derk, Chris T. and Jimenez, Sergio A., "Acute myocardial infarction in systemic sclerosis patients: a case series" (2007). Department of Medicine Faculty Papers. Paper 18.

https://jdc.jefferson.edu/medfp/18

This Article is brought to you for free and open access by the Jefferson Digital Commons. The Jefferson Digital Commons is a service of Thomas Jefferson University's Center for Teaching and Learning (CTL). The Commons is a showcase for Jefferson books and journals, peer-reviewed scholarly publications, unique historical collections from the University archives, and teaching tools. The Jefferson Digital Commons allows researchers and interested readers anywhere in the world to learn about and keep up to date with Jefferson scholarship. This article has been accepted for inclusion in Department of Medicine Faculty Papers by an authorized administrator of the Jefferson Digital Commons. For more information, please contact: JeffersonDigitalCommons@jefferson.edu. 


\title{
Acute myocardial infarction in systemic sclerosis patients: a case series
}

\author{
Chris T. Derk 'Sergio A. Jimenez
}

Division of Rheumatology, Thomas Jefferson University, 613 Curtis

Building, 1015 Walnut Street, Philadelphia, PA 19107-5541

e-mail: Chris.Derk@jefferson.edu

Tel.: +1-215-955-1410

\begin{abstract}
To characterize the clinical manifestations of patients with systemic sclerosis who develop a myocardial infarction (MI), a retrospective review of the medical records of all patients who were admitted to our institution between 1982 and 2002 and had the dual diagnosis of systemic sclerosis and an acute MI was done. From 1,009 systemic sclerosis hospital admissions, 11 (1.09\%) were for an acute MI. Three of these patients had normal coronaries, and instead of wall motion abnormalities, left ventricular hypertrophy was the predominant finding of an echocardiography. The odds ratio of finding normal coronaries in systemic sclerosis vs the general population who develops an acute MI is 33.89 (14.0881.39). Seven of our patients had an elevated creatinine level on presentation. Acute $\mathrm{Ml}$ is an uncommon manifestation in systemic sclerosis patients. Normal coronaries are seen more commonly in these patients as compared to the general population, while vascular, gastrointestinal, and renal involvement is prevalent in these patients.
\end{abstract}

Keywords Acute myocardial infarction 'Coronary artery disease Raynaud's phenomenon 'Systemic sclerosis 'Tissue fibrosis

\section{Introduction}

Endothelial cell dysfunction is one of the fundamental abnormalities in the pathogenesis of systemic sclerosis causing a progressive vasculopathy most commonly involving the microvasculature system. Less frequently, the vasculopathy of systemic sclerosis may affect larger vessels. The most common clinical manifestation of systemic sclerosis vasculopathy is Raynaud's phenomenon, and involvement of the kidneys, lungs, and the heart has been extensively described. The vessels most commonly involved are 
small arterioles (500-50 $\mu$ in diameter) and capillaries. Only rarely has involvement of larger vessels been described [1, 2].

Cardiac involvement in systemic sclerosis is not uncommon, occurring in approximately $20-25 \%$ of patients [3-5]. The most prevalent clinical manifestations are angina, conduction defects, myocardiopathies related to myocardial fibrosis, and arrhythmias. A coronary artery vasospastic phenomenon ("Raynaud's phenomenon") has also been described, and it has been suggested that this alteration may cause myocardial ischemia with angina symptoms as well as reperfusion injuries, leading to the development of myocardial fibrosis [6].

The aim of this study was to characterize the clinical manifestations of patients with systemic sclerosis who were hospitalized at our institution for an acute myocardial infarction (MI) between the years 1982 and 2002 and to identify a subgroup of patients from this cohort who did not exhibit coronary vessel atherosclerosis by cardiac catheterization or postmortem studies. The clinical characteristics of this subgroup of patients were examined in detail and were compared to historical control cases of non-atherosclerotic Mls in the general population.

The prevalence rate of MI with normal to near-normal coronary arteries in the general population varies between 1 and $12 \%$ depending on the definition of "normal coronary vessels" [7-10]. This pattern is more commonly seen in younger individuals. In patients below 30 years of age, it accounts for $16-35 \%$ of Mls [11]. The etiology of this syndrome is not clearly defined at this time, although endothelial dysfunction, coronary microembolism, coronary vasospasm, an imbalance in oxygen supply and demand, and nonatherosclerotic coronary artery disease have been postulated as likely mechanisms.

\section{Patients and methods}

The inpatient medical record database of our institution, which is a tertiary, university-based referral center, with a scleroderma clinic that draws patients predominantly from the northeast part of the USA, was searched using the diagnostic codes for systemic sclerosis and acute Ml. Cases were located among admissions between 1982 (when the computerized database was first established at our institution) and 2002. Twelve patients who 
carried the dual diagnosis of systemic sclerosis and acute MI were identified based on the diagnostic codes used, which included coding changes implemented through the years of ascertainment. The study was approved by the Institutional Review Board. A thorough evaluation of the medical records allowed us to confirm the diagnosis of systemic sclerosis in all except one of the patients identified. All patients had a clearly defined history of MI which was based on electrocardiographic changes and at least a twofold increase in myocardial creatine kinase activity on presentation. The demographic data of each patient being admitted to the hospital for a MI were collected. The presence and severity of systemic sclerosis visceral organ involvement were assessed employing a previously described systemic sclerosis severity scale [12]. In this scale, involvement of nine specific organs is rated from 0 (no documented involvement) to 4 (end-stage disease).

Statistical analyses Quantitative data are presented as a mean with a standard deviation, while qualitative data are presented as a percentage of the total or as a ratio. The patients for whom clinical, radiologic, or pathologic reports were not adequate to delineate whether they had atherosclerotic cardiovascular disease were assumed to have atherosclerosis to obtain the most conservative estimate of nonatherosclerotic disease in the cohort studied.

Employing historical controls from a similarly designed retrospective cohort study which examined $\mathrm{Ml}$ admissions in the general population with angiographically normal coronary arteries, we calculated the odds ratio of having angiographically normal coronary arteries in systemic sclerosis patients who had a recent $\mathrm{MI}$ as compared to the general population, and a 95\% confidence interval is given [4].

\section{Results}

From 1,009 systemic sclerosis hospital admissions to our institution between 1982 and 2002, 11 (1.09\%) were for an acute MI. The average age of this group of patients was $64.4 \pm 7.9$ years old. Six patients were women (54.5\%), nine were white $(81.8 \%)$, and two were African-American (18.2\%). Seven patients had limited cutaneous systemic sclerosis (LcSSc) $(63.6 \%)$, and four patients had diffuse cutaneous systemic sclerosis (DcSSc) (36.4\%).

Prevalent clinical symptoms related to systemic sclerosis were gastrointestinal (91\%), peripheral vascular (81.8\%) (seven out of nine with severe Raynaud's phenomenon), and renal (36.4\%). The 
extent of skin involvement based on total body surface clinically affected by the sclerotic process was $15.1 \pm 12.3 \%$ (Table 1 ). Modified Rodnan skin scores were not performed during the inpatient hospitalization. Seven out of nine patients had positive antinuclear anti-bodies. None of eight patients tested for anticardiolipin antibodies were positive, and only one of eight tested for lupus anticoagulant was positive. On presentation, 8 of 11 patients had substernal chest pain, and 3 of 11 had orthopnea and dyspnea. Mean initial creatinine phosphokinase (CK) was 608 $\pm 366 \mathrm{IU} / \mathrm{l}$ and CK-MB, 57.6 $\pm 47.7 \mathrm{IU} / \mathrm{l}$ (normal values for CK and CK-MB were 30-170 and 0-7 IU/I, respectively.) Mean creatinine level was $2.09 \pm 0.69 \mathrm{mg} / \mathrm{dl}$. Out of 11 patients, 4 had typical clinical and laboratory manifestation of scleroderma renal crisis on admission. Out of 11 patients, 2 had new-onset atrial fibrillation, and 4 out of 11 had electrocardiographic evidence of intraventricular conduction abnormalities. On chest X-ray evaluation $45.4 \%$ of patients had signs of congestive heart failure, $27.2 \%$ had pleural effusions, and $27.2 \%$ had interstitial lung fibrosis changes. Initial blood pressure was $134 \pm 17.8 / 77 \pm 12.4 \mathrm{~mm} \mathrm{Hg}$. Five patients had clearly defined atherosclerotic changes by cardiac catheterization or examination of autopsy specimens $(45.4 \%)$, whereas three (27.2\%) patients had normal coronary arteries. In three cases the atherosclerotic status could not be clearly defined. Out of 11 patients, 9 developed non-Q wave Mls. All three of the nonatherosclerosis patients displayed this pattern. On two-dimensional (2-D) echocardiography upon admission to the hospital, the nonatherosclerotic cases showed no wall motion abnormalities but concentric left ventricular hypertrophy (LVH) as compared to the patients with atherosclerotic heart disease who had wall motion abnormalities but no LVH. Four patients died during these admissions, two from infections and two from cardiogenic shock. From three autopsies performed, two patients had moderate coronary atherosclerosis. The autopsy of the third patient did not show any atherosclerotic changes, but perivascular fibrosis of the coronary vessels and a diffuse lymphocytic infiltrate of the myocardium were observed (Figs. 1 and 2).

Using as a historical control a previous retrospective study of 23 patients who had normal coronary arteries on angiography out of a total 2,100 acute $\mathrm{Ml}$ admissions [7], we calculated a significantly higher odds of having normal coronary arteries in patients with systemic sclerosis and an acute myocardial infarct as compared to a control population (OR 33.86, 95\% Cl 14.08-81.39). 


\section{Discussion}

Acute $\mathrm{MI}$ is an uncommon complication of SSc. It has been suggested that some cases of $\mathrm{Ml}$ in these patients may be caused by coronary vasospasm rather than by atherosclerotic coronary disease [6]. Indeed, thallium perfusion studies have provided strong evidence that perfusion defects are common in patients with systemic sclerosis and can occur both at rest and in response to cold pressor provocation [13-16]. Because there is no evidence of an increased risk for coronary atherosclerosis in this disease, it is most likely that endothelial dysfunction plays a central role in the involvement of the coronary vessels. The pathogenesis of coronary vessel alterations in systemic sclerosis has been hypothesized to result in a combination of both the typical microvascular disease often present in SSc and atherosclerotic disease. It has been suggested that perivascular cellular infiltrates with activated $T$ cells are responsible for the production and secretion of cytokines such as transforming growth factor (TGF)- $\beta$, which injure the endothelial cells and cause an increased expression of major histocompatibility complex (MHC) class I and II antigens as well as of the adhesion ligand intracellular adhesion molecule-1. Chemoattraction of fibroblasts into the vessel wall most likely under the influence of locally secreted TGF- $\beta$ and their subsequent transdifferentiation into myofibroblasts capable of increased production of collagens and other extracellular matrix proteins cause a reduction in the coronary lumen and vasomotor instability. These changes in the vessel wall lead to endothelial injury, with exposure of the subendothelium causing subsequent platelet aggregation and thrombus formation [1]. In autopsy studies extramural coronary vessels are often normal, while smaller intramural vessels show intimal proliferation and intravascular thrombosis [17-19].

Cardiac wall motion abnormalities on 2-D echocardiography were surprisingly absent in all three patients who did not have atherosclerotic coronary artery disease, although concentric LVH was uniformly present. In contrast, in patients who had atherosclerotic disease, there were pronounced myocardial motion abnormalities without LVH. These observations suggest that coronary ischemia related to coronary vasospasm may be responsible for the occurrence of $\mathrm{MI}$ in patients with SSc.

In our case series, $64 \%$ of SSc patients who developed MI had a creatinine level of more than $1.3 \mathrm{mg} / \mathrm{dl}$, and four were in 
scleroderma renal crisis. While this may be in line with early investigators who suggested that cardiac involvement in SSc may be a manifestation of disease in other organs such as the kidneys and the lungs [20], and the heart is involved secondary to the associated systemic and pulmonary hypertension, it may also represent a similar pathogenic process which leads these patients to both have coronary and peripheral vascular involvement.

Acknowledgements Support was provided by National Institutes of Health grant AR19616 (S.A.J.). Dr. Derk was supported by National Institutes of Health training grant AR07583.

\section{References}

1. Jimenez SA, Derk CT (2004) Following the molecular pathways toward an understanding of the pathogenesis of systemic sclerosis. Ann Intern Med 140:37-50

2. Guiducci S, Pignone A, Matucci-Cerinic M (2004) Raynaud's phenomenon in systemic sclerosis. In: Clements PJ, Furst DE (eds) Systemic sclerosis. Lippincott, Philadelphia, pp 221-240

3. Eason RJ, Tan PL, Gow PJ (1981) Progressive systemic sclerosis in Auckland: a ten year review with emphasis on prognostic features. Aust N Z J Med 11:657-662

4. Lally EV, Jimenez SA, Kaplan SR (1988) Progressive systemic sclerosis: mode of presentation, rapidly progressive disease course, and mortality based on an analysis of 91 patients. Semin Arthritis Rheum 18:1-13

5. Hata N, Kunimi T, Matsuda H et al (1998) Cardiac disorders associated with progressive systemic sclerosis. J Cardiol 32 (Suppl):397-402

6. Follansbee WP (1996) Organ involvement: cardiac. In: Clements PJ, Furst DE (eds) Systemic sclerosis. Lippincott, Baltimore, pp 333-364

7. Ammann P, Marschall S, Kraus M et al (2000) Characteristics and prognosis of myocardial infarction in patients with normal coronary arteries. Chest 117(2):333- 
8. Sharifi M, Frohlich TG, Silverman IM (1995) Myocardial infarction with angiographically normal coronary arteries. Chest 107(1):36-40

9. Legrand V, Deliege M, Henrard L et al (1982) Patients with myocardial infarction and normal coronary arteriogram. Chest 82(6):678-685

10. Raymond R, Lynch J, Underwood D et al (1988) Myocardial infarction and normal coronary arteriography: a 10 year clinical and risk analysis of 74 patients. J Am Coll Cardiol 11(3): 471-477

11. Weinberger J, Rotenberg Z, Fuchs J et al (1987) Myocardial infarction in young adults under 30 years: risk factors and clinical course. Clin Cardiol 10(1):9-15

12. Medsger TA Jr, Silman AJ, Steen VD et al (1999) A disease severity scale for systemic sclerosis: development and testing. J Rheumatol 26(10):2159-2167

13. Kahan A, Devaux JY, Amor B et al (1986) Nifedipine and thallium-201 myocardial perfusion in progressive systemic sclerosis. N Engl J Med 314:1397-1402

14. Alexander EL, Firestein GS, Weiss JL et al (1986) Reversible cold-induced abnormalities in myocardial perfusion and function in systemic sclerosis. Ann Intern Med 105:661-668

15. Follansbee WP, Kiernan JM, Curtiss El et al (1987) Coldinduced thallium perfusion abnormalities in diffuse scleroderma and Raynaud's disease: response to diltiazem therapy. Arthritis Rheum 30(Suppl 4):S117

16. Gustafson R, Mannting F, Kazzam E et al (1989) Coldinduced reversible myocardial ischaemia in systemic sclerosis. Lancet 2 (8661):475-479

17. Bulkley BH, Klacsmann PG, Hutchins GM (1978) Angina pectoris, myocardial infarction and sudden cardiac death 
with normal coronary arteries: a clinicopathological study of 9 patients with progressive systemic sclerosis. Am Heart J 95:563-569

18. Follansbee WP, Miller TR, Curtiss El et al (1990) A controlled clinicopathologic study of myocardial fibrosis in systemic sclerosis. J Rheumatol 17:656-662

19. D'Angelo WA, Fries JF, Masi AT et al (1969) Pathologic observations in systemic sclerosis: a study of 58 autopsy case and 58 matched controls. Am J Med 46:428-440

20. Sackner MA, Akgun N, Kimbel P et al (1964) The pathophysiology of scleroderma involving the heart and respiratory system. Ann Intern Med 60:611-630

\section{Table \& Figures}

Table 1 Demographics of 11 SSc patients with acute myocardial infarction

\begin{tabular}{lc}
\hline Age (years) & $64.4 \pm 7.9$ \\
Sex (\%) & \\
Female & 54.50 \\
Race (\%) & \\
White & 81.80 \\
African-American & 18.20 \\
Clinical subset of SSc (\%) & \\
Limited & 63.60 \\
Diffuse & 36.40 \\
SSc symptoms (\%) & \\
Gastrointestinal & 91 \\
Raynaud's phenomenon & 81.80 \\
Renal involvement & 64 \\
TBS skin involvement & $15.1 \pm 12.3$
\end{tabular}

SSc Systemic sclerosis, TBS total body surface 
Fig. 1 Perivascular hyperplasia with fibrous deposition in a small coronary vessel without atheroma and with total lumen occlusion.

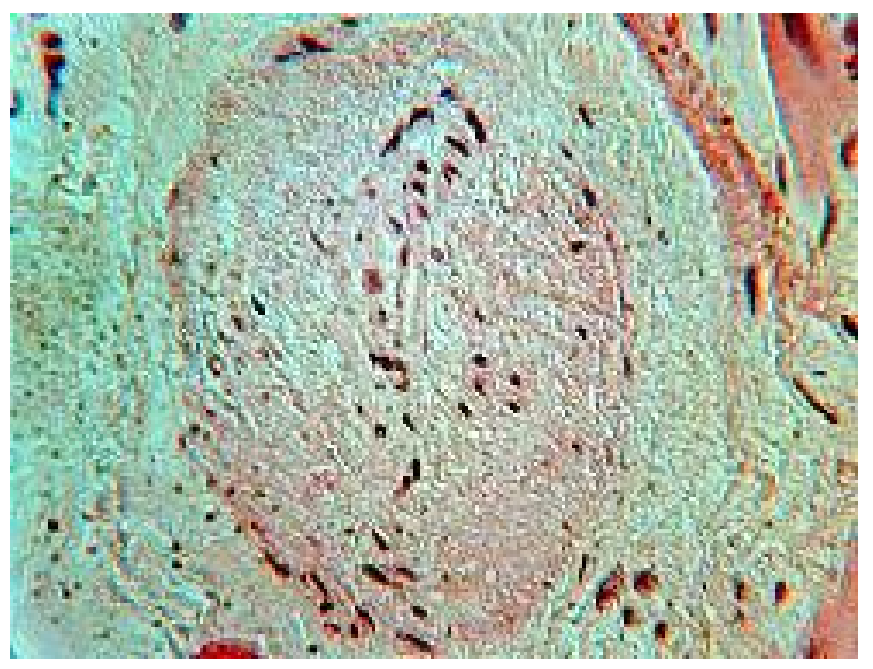

Fig. 2 Diffuse lymphocytic infiltrates of the myocardium

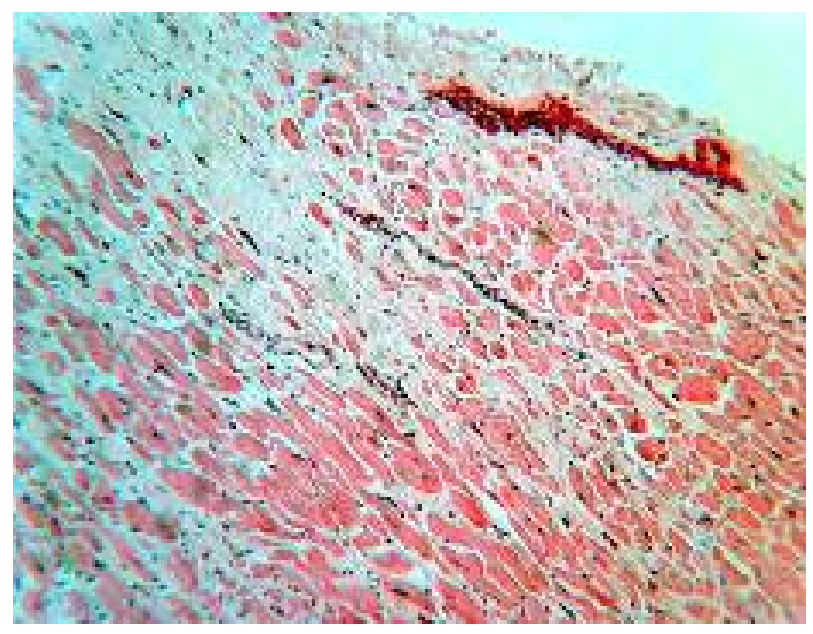

